\title{
Core competency requirements among extension workers in Peninsular Malaysia: use of Borich's needs assessment model
}

\begin{abstract}
The study described the perceived importance of, and proficiency in core agricultural extension competencies among extension workers in Peninsular Malaysia; and evaluating the resultant deficits in the competencies. The Borich's Needs Assessment Model was used to achieve the objectives of the study. A sample of 298 respondents was randomly selected and interviewed using a pre-tested structured questionnaire. Thirty-three core competency items were assessed. Instrument validity and reliability were ensured. The cross-sectional data obtained was analysed using SPSS for descriptive statistics including mean weighted discrepancy score (MWDS). Results of the study showed that on a scale of 5, the most important core extension competency items according to respondents' perception were: "Making good use of information and communication technologies/access and use of webbased resources" ( $\mathrm{M}=4.86, \mathrm{SD}=0.23)$; "Conducting needs assessments" $(\mathrm{M}=4.84, \mathrm{SD}=0.16)$; "organizing extension campaigns" $(\mathrm{M}=4.82, \mathrm{SD}=0.47)$ and "Managing groups and teamwork" $(\mathrm{M}=4.81, \mathrm{SD}=0.76)$. In terms of proficiency, the highest competency identified by the respondents was "Conducting farm and home visits $(\mathrm{M}=3.62, \mathrm{SD}=0.82)$ followed by 'conducting meetings effectively' $(\mathrm{M}=3.19, \mathrm{SD}=0.72)$; "Conducting focus group discussions" $(\mathrm{M}=3.16, \mathrm{SD}=0.32)$ and "conducting community forums" $(\mathrm{M}=3.13, \mathrm{SD}=0.64)$. The discrepancies implying competency deficits were widest in "Acquiring and allocating resources" (MWDS=12.67); use of information and communication technologies (ICTs) and web-based resources in agricultural extension (MWDS=12.59); and report writing and sharing the results and impacts (MWDS=11.92). It is recommended that any intervention aimed at developing the capacity of extension workers in Peninsular Malaysia should prioritize these core competency items in accordance with the deficits established in this study.
\end{abstract}

Keyword: Agricultural extension; Capacity development; Core competency; Peninsular Malaysia 